\title{
VIRTUAL FLIPPED CLASSROOM: NEW TEACHING MODEL TO GRANT THE LEARNERS KNOWLEDGE AND MOTIVATION
}

\author{
Sameh S. Ismail ${ }^{1,2}$ iD, Shubair A. Abdulla ${ }^{1}$ \\ ${ }^{1}$ Sultan Qaboos University (Oman) \\ ${ }^{2}$ Cairo University (Egypt) \\ samehsaid@squ.edu.om,shubair@squ.edu.om
}

Received May 2018

Accepted October 2018

\section{Abstract}

This research introduces a new pedagogical approach, the Virtual Flipped Classroom (VFC). The VFC is an integration of two concepts: the Flipped Classroom and Virtual Classroom. It enables teachers to teach and guide students in applying the activities needed to achieve the best learning levels. To investigate the effect of VFC, the researchers applied it to students on a computer programming course in the Instructional and Learning Technology (ILT) department at the College of Education, Sultan Qaboos University (SQU). The students' learning achievements and motivation were measured by two instruments, the Programming Achievement Test and Survey of Student Motivation respectively. Onegroup pretest-posttest qusai-experimental design was followed. The sample, which consisted of 18 students, was taught some selective topics of the computer-programming perquisite using the VFC model. A pretest and posttest are administered before and after using the VFC model. The researchers used independent sample t-tests and multivariate analysis of variance (MANOVA) to analyse the data obtained. The findings indicated a significant difference in learning achievement and motivation before and after applying the VFC model. The differences indicate that the VFC model is beneficial to student outcomes. Further analysis showed that the new model contributed to the improvement of performance of low achieving students.

Keywords - Virtual flipped classroom, Flipped classroom, Virtual classroom, Achievement levels, Motivation, Computer programming.

\section{To cite this article:}

Ismail, S.S., \& Abdulla, S.A. (2019). Virtual flipped classroom: new teaching model to grant the learners knowledge and motivation. Journal of Technology and Science Education, 9(2), 168-183. https://doi.org/10.3926/jotse.478

\section{Introduction}

Computer programming is crucial in today's world (Lye \& Koh, 2014). Technology has developed to the point whereby most people probably rely on smartphone apps to manage their daily tasks. All of these apps are fuelled by computer programming. Currently, we are living in a world where computer programs are found nearly everywhere. For instance, smartphones are a combination of computer programs and technology, Google Glass is the combination of computer programs and glasses, and smart watches are 
the union of computer programs with watches. For educational technology specialists, computer programming also plays a crucial role. Being exposed to coding gives them an appreciation of what can be done with computer programming. The truth is that most of our instructional and learning systems are based on learning management systems; many instructors and trainers globally use online learning platforms to create and manage courses, deliver self-paced online or blended courses, provide secure instructional video streaming, and conduct advanced tests and assessment sessions (Ismail \& Shubair, 2015; Kahn \& Spiegel, 1999; Park, 2016; Choi, Kopcha, Mativo, Hill, Hodge, Shin et al., 2016). Without computer programming, the whole learning system could collapse. Computer-programming courses are essential for preparing educational technology specialists and allow them to meet the challenges in their daily professional lives. This fact has been realized at the Department of Instructional and Learning Technologies, College of Education at SQU. Two computer-programming courses have been added to the bachelor programme. These courses aim to provide students with the technical knowledge and skills to develop and implement computer solutions that accomplish goals important in any educational environment.

Researchers have noticed a sign of low level in the performance of students in computer programming courses at SQU. This was noted through the grades of the current students as well as the previous years' students in tests and through their interactions and responses during class time. After reviewing the departmental programme, the researchers concluded that the computer programming courses lack prerequisite programming knowledge, which is specific knowledge that must be obtained before a student can take a course of this type. Such prerequisite knowledge is usually at a lower level of the same course subject. From an academic perspective, prerequisite knowledge is very crucial since it helps the teacher to teach at a certain academic level and provides the students with knowledge and skills that help them feel more confident with the subject matter. Ignoring the need for prerequisite knowledge will result in difficulties in learning the needed skills to achieve success in the next level.

To engage students in computer programming more effectively, the programme should provide ideas about the computational approaches to problem-solving, computational modes of thinking, and mathematical and logic aptitude, which are essential to understanding computer programming and might be granted by prerequisite knowledge i.e. discrete math, data structure and algorithms, and logic design. The researchers conducted an online quiz to evaluate the students' fundamental knowledge of computer programming. The results of the quiz indicated that the students had a significant low level of knowledge. For example, many students had difficulty in applying the if-statement to some data structures and failed in the fundamental operations associated with a variety of data structures as they did not have the basic background. As the number of hours in the students' plan does not allow a new course to be added that provides the prerequisite knowledge of computer programming, the researchers tried to allocate extra contact hours to teach the students this knowledge, however, the credit hours system and the inability to determine the time for all students prevented this from taking place.

Therefore, the main point of this study is to determine what prerequisite knowledge is necessary for computer programming students. The researchers planned to deliver this content and make it available through the use of a flipped classroom. To deal with the difficulties and problems related to the content, and to collaborate in solving problems in the computer programming, there was the clear need for a new learning environment that provides interaction between the instructor and the students and between the students themselves. This learning environment was provided by the virtual classroom. As a result, the researchers integrated the concept of the Flipped Classroom with the concept of the Virtual Classroom to devise a new teaching model, the Virtual Flipped Classroom (VFC).

\subsection{Purpose of the Research}

This research aims to solve the problem caused by the lack of time and classrooms needed to supervise and guide the students in learning the prerequisite knowledge needed for the programming course at SQU through the VFC model. This model helps students learn the prerequisite knowledge required to undertake more advanced programming courses. This research tries to answer the following questions: 
1. What is the VFC?

2. Is the VFC effective in providing students the knowledge they need?

3. Is the VFC effective in solving problems in computer programming?

4. Is the VFC effective in increasing the motivation of students to learn computer programming?

\subsection{Significance of the Research}

The significance of the research is represented by providing students with a new learning environment that delivers the prerequisite knowledge required to undertake more advanced programming courses. The use of our new VFC model will increase student motivation and promote prerequisite knowledge, which consequently improves the learning experience of computer programming. In addition, the use of the VFC model will provide opportunities to facilitate learning through the ability of recording and replaying the lectures devoted to teaching prerequisite knowledge for computer programming.

\section{Literature Review}

The Active Learning (AL) approach has been roundly debated in the field of education. It is related to the students' performance, assimilate, and knowledge and skills mastering. Hence, researchers and educators have been investigating methods and strategies that achieve AL and ensure student learning and interaction in the classroom through a variety of activities (Sesen \& Tarhan, 2010; Patrick, Howell \& Wischusen, 2016). The Flipped Classroom (FC) is considered an efficient strategy to achieve AL, both in and out of the classroom (Szarek, Boardman, White \& Holt, 2016). The strategy of FC serves both teaching and learning by flipping course lectures and homework in a hyper multimedia videos which are posted online so that students can view and study them as many times as they like before classes start (Slomanson, 2014). These videos can be produced by the teachers themselves or assembled from a videosharing website i.e. YouTube, Khan Academy, and PresentationTube. In some cases, teachers instruct a small group of learners to create multimedia videos either by recording specific scenes or capturing screencasts of computer activities. In all cases, both learners and teachers will benefit from applying the FC strategy. Learners can watch lectures at any place or time and utilize classroom time to do their homework. Teachers can support students to become self-directed learners instead of telling them what to learn, how to learn, and when to learn, enhancing their critical thinking and self-learning (Sun, Wu \& Lee, 2017), constructing experiences, developing communication skills and cooperation, increasing the learning motivation, and hence increasing their achievement (Sun \& Wu, 2016).

The role of teachers in the FC strategy differs significantly from their roles in traditional classrooms. They manage the class and the time, control the speed of learning, determine the strategies and activities that will be applied, direct the students' activities, and motivate and provide them with the support needed. They also participate in discussion groups by leading the discussion and concluding the essential points. Teachers are able to determine the strengths and weaknesses in student learning and consequently instruct and guide the students positively. In addition, the teachers' role in planning the lesson differs as well. They become more effective in refining lesson plans that suit the students' needs. The core of their focus is to achieve better understanding for students. The teacher's role in the FC strategy is redefined as that of guide, coach, and facilitator (Bergmann \& Sams, 2012; Hamdan, McKnight, McKnight \& Arfstrom, 2013). No benefits can be obtained from applying the traditional classroom technique.

The FC strategy has articulated four pillars identified by the Flipped Learning Network. To implement the strategy, the following four pillars should be present (Bergmann \& Sams, 2014; Long, Logan \& Waugh, 2016):

- Flexible environment: Tools and resources that are custom designed or created to promote the language communication as the intended outcome.

- Learning culture: Teachers need to consider the type of learners and their personalities, socioeconomic status, cognitive abilities, and language proficiency in choosing an instructional methodology. 
- Intentional content: The lesson, teaching, and assessment plans are intentionally selected for the outof-class portion and leveraged for the in-class portion.

- Professional educator: Teachers should know the teaching material and their students in order to develop a plan to move learners forward. Thus, they must be planners, managers, facilitators, coaches, problem solvers, and researchers.

The virtual classroom (VC) can be defined as a computer-based environment in which AL can be applied since almost everything that can be done in a real classroom can be done in a virtual one. The VC teacher's role is not much different from that in the real classroom. Students and teachers can collaborate using multiple communication channels such as audio, video, chat, and whiteboard. The VC environment provides students and teachers with the possibility to communicate both synchronously and asynchronously. The synchronization environment of VC effectively raises student satisfaction (Thomson, 2010) and has an effect on the social side of education (Martin, Parker \& Deale, 2012). In addition, using a synchronous virtual classroom gives students the opportunity to: interact with the teacher and other students, obtain immediate feedback from teachers, enhance dynamic interactions with other participants, strengthen their social presence, exchange the emotional supports, and supply verbal elements (Allmendinger, Kempf \& Hamann, 2009; Lietzau \& Mann, 2009). The asynchronous environment of VC is a digital environment that enables students to participate in activities any time, any place. This feature overcomes the problem of attending classes in real-time and takes into account individual differences.

VC technologies have evolved and expectations for quality are higher than ever (Martin \& Parker, 2014). Some recent technologies include sending messages to selected users (e.g. private messages), texting and drawing graphics and diagrams (e.g. E-Board), sharing software and files between teachers and students (e.g. application sharing and file transfer), viewing PowerPoint slides and video clips, asking survey questions in real time to students (e.g. polling), dividing students into small groups based on their characteristics or their levels (e.g. breakout rooms), and live recording of lessons to be able to watch and review them at a later time (Marlowe, 2012; Parker \& Martin, 2010). Some famous synchronous VC environments include Adobe Connect, Blackboard, WebEx, Centra, Anymeeting, DimDim and WIZIQ.

\subsection{What is the VFC?}

This section will answer the first research question: What is the VFC?

For the case in hand, there are no restrictions that ensure that students entering the computer-programming course have some prior knowledge. When the researchers decided to deliver this knowledge through a new prerequisite course in a traditional classroom (Figure 1a), the main challenge was that the bachelor programme of the ILT students prevents adding any kind of prerequisite courses. They attempted to replace part of the computer-programming course with the prerequisite knowledge needed. Unfortunately, the number of weeks in one semester is barely enough to cover the content of the course. The researchers also attempted to hold extra lecture hours out of the students' official class hours but they could not find free time and a suitable place for all registered students.

Accordingly, the researchers suggested teaching the prerequisite knowledge by employing the FC strategy. This strategy is extremely helpful and the programming students will learn the prerequisite knowledge at their own pace and according to their schedule. The FC strategy involves two stages, as depicted in Figure 1b:

- Self-learning stage: in this stage, the teacher provides video lectures out of the classroom's official time to avoid the problem of a lack of classrooms and time.

- Interactive activities in the classroom stage: the teacher in this stage performs plenty of individual and group activities to deepen the students learning. 
Again, we faced the same challenge to complete stage two - a lack of classrooms and time. The VC environment is the only useful way in this case as it is a learning environment that allows the students and teachers to communicate with each other without the need to be physically together at the one time. To overcome all of these challenges, the researchers' suggestion was to merge the FC strategy with the VC environment to produce a new learning model referred to as the Virtual Flipped Classroom (VFC). The VFC allows the students to watch and listen to lectures at home and then perform their interactive activities and apply their knowledge in a virtual synchronized classroom in a way similar to the real classroom environment. Figure 1-c depicts the VFC model.

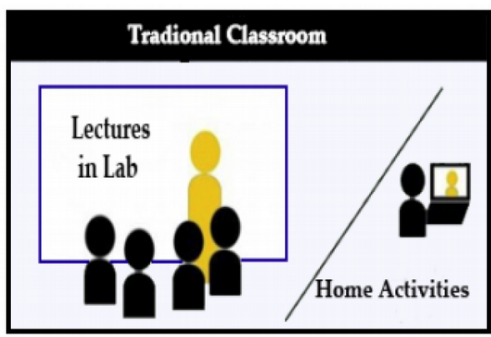

(a)

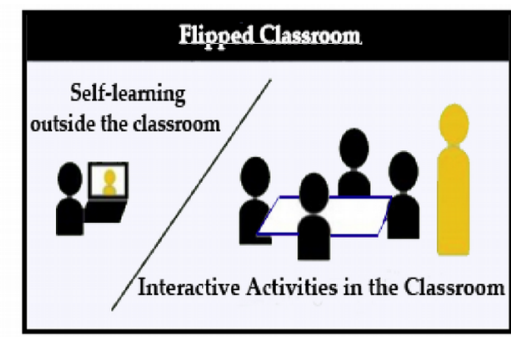

(b)

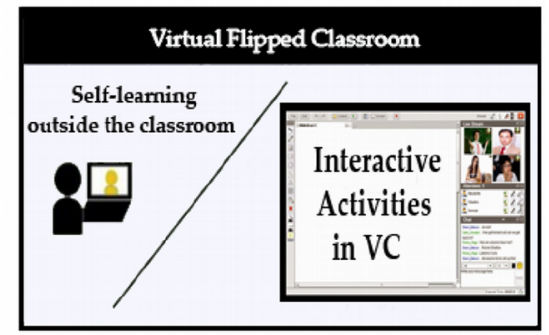

(c)

Figure 1. Traditional classroom, flipped classroom, and virtual flipped classroom models

\section{Methodology}

\subsection{Participants}

The sample used in the current research consists of a total of 18 students, 3 males and 15 females, from two different cohorts, 2012 and 2013. All the students in the sample are studying at the Department of Instructional and Learning Technologies in the College of Education, SQU. They registered in the computer programming course because it is compulsory in their major.

\subsection{Research Design}

A quasi-experimental design has been followed in this research. To find out the effect of the VFC model on student performance, the researchers followed a one-group pretest-posttest design. This kind of research design increases the statistical power of measuring the effect of the VFC model. The experiments lasted for one academic semester using some selective topics that can be considered perquisites of the computer programming course such as algorithmic thinking ability and computer programming ability. Six multimedia video lessons were prepared to teach the topics and these were enriched by active-learning activities such as real-world problem-solving cases and interactive questions. A pretest was given to the participants prior to applying the VFC model to measure their prerequisite knowledge, and then the researchers applied the VFC model using the six multimedia videos. After that, a posttest was administered to measure the students' prerequisite knowledge again.

\subsection{Instruments}

We designed two instruments: Programming Achievement Test (PAT) and Survey of Student Motivation (SSM). The main goal of these instruments is to measure students' levels of learning and motivation using the FVC model.

\subsubsection{Programming Achievement Test (PAT)}

The Programming Achievement Test (PAT) is the first instrument used in this research. Two versions of PAT were administered: (i) "PAT1", to measure the students' knowledge in computer programming and (ii) "PAT2", to measure the students' ability in solving real-world problems. The same content was used in the pretest and posttest for both versions; however, the order of the test items in the posttest was changed to avoid the same-set-response effect. The content validity of the two versions of PAT was determined by 
a panel of experts. We made all the necessary changes in the content to address the panel's concern before the administration of the tests. For the first version, the test items comprised 30 multiple-choice questions (MCQ) on the concept of decision structure, which allows programs to control which statements are executed and when. Sixty minutes were allotted for the test. For each MCQ, there was one mark, with the final score then being calculated out of a total of 10. In the second version, the students' ability for solving real-world problems was measured by asking them to write the corresponding programs in VB.NET to sole the following problems: (1) finding the students in probation list, (2) finding the maximum student's grade, and (3) sorting three numbers in ascending order. The program must contain one or two IF-statements, i.e. if ... then, if ... then ... else, and if ... then ... else if. Forty minutes were allotted for this version of PAT.

\subsubsection{Survey of Student Motivation (SSM)}

The survey of student motivation (SSM) is the second instrument used in this research. The SSM is designed based on Keller's course interest survey (Keller, 1999), with some adaptation to fit the goal of our research. The SSM was distributed among the participants as pretest and posttest. It consisted of 25 items categorized into four parts: Attention, Relevance, Confidence, and Satisfaction (ARCS). Using the Likert-type 5-point scaling of items, SSM was administered to the participants for 25 minutes. The content validity of the SSM was determined by a panel of experts. The reliability is established by applying it to a pilot sample of 14 students out of the research sample. The reliability estimation is obtained using Cronbach's alpha measure. The overall reliability estimation was 0.715 , which refers to an acceptable reliability. The reliability value ranged from $0.824-0.899$, as shown in Table 1 , which indicates Cronbach's alpha measurements for the categories of SSM items.

\begin{tabular}{|c|r|r|}
\hline Items Category & Number of Items & Cronbach's Alpha \\
\hline Attention & 6 & 0.898 \\
\hline Relevance & 6 & 0.886 \\
\hline Confidence & 7 & 0.824 \\
\hline Satisfaction & 6 & 0.899 \\
\hline Total & 25 & 0.715 \\
\hline
\end{tabular}

Table 1. Cronbach's alpha measurements for the categories of SSM items

\subsection{Production Materials}

The content has been developed for video lessons that covered three topics: algorithms and flowcharts, modularity, and logic. Six video lessons have been produced with a total of 4 hours and 10 minutes. Each lesson includes objectives learning, lesson content, and evaluation. Each video required the following four production stages:

- Planning: this stage involved introducing the lesson objective, preparing the lesson content perfectly by concentrating on clarity and removing fillers and repetitions, in addition to suggesting a suitable platform for publishing the videos online.

- Recording: in this stage, a digital camera or screen capture software was used to produce the video lessons.

- Editing: this stage is crucial in making sure the video flows in a way that achieves the instructional goals. It can take a relatively long time. It aims at improving the videos lessons, and involves adding footage, effects, music or graphics, removing unwanted footage, titling, colour correction, or sound mixing.

- Publishing: the final stage aims to publish video lessons securely to a video hosting online platform which will be easily viewed on the students' laptops and mobile devices. 
To get the students interested in learning the content, we produced it in a fun and interesting way by adding a game that involved building a Tic-Tac-Toe game. The inclusion of several examples of codes has been taken into account in the production of videos to simplify the concepts and knowledge. Following a gradual procedure in the explanation along with using images, videos, and instructional flash files (SWF files) is also taken into account. After describing the lesson content, the formative evaluation is conducted. All the videos are produced using the Screencast-O-Matic software, which is a free screen and webcam recorder used to capture video from a computer screen. We used Google Drive to upload the videos and share them with the students. Figure 2 shows snapshots of two videos to explain how to design the Tic-Tac-Toe game interface (left) and to write some needed codes to control the game (right). The videos produced are detailed in Table 2.
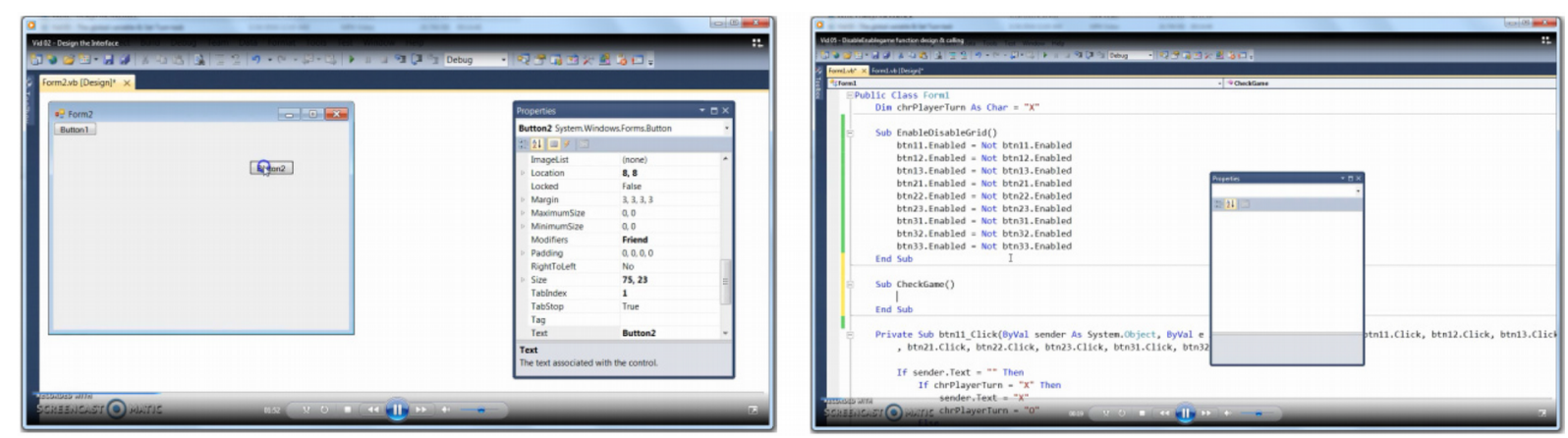

Figure 2. Snapshots of video lessons

\begin{tabular}{|c|c|c|c|}
\hline \# & Video topic & Duration & Formative evaluation \\
\hline 1 & - Algorithms and flowcharts & $0: 35: 17$ & Verbal questions \\
\hline 2 & $\begin{array}{l}\text { - Demonstrating the Tic-Tac-Toe game } \\
\text { - Design the Interface }\end{array}$ & $0: 39: 20$ & Assignment \\
\hline 3 & - The logic & $0: 43: 46$ & Verbal questions \\
\hline 4 & - Functions and procedures & $0: 44: 24$ & Verbal questions \\
\hline 5 & - Modularization of Tic-Tac-Toe game & 0:48:01 & Verbal questions \\
\hline 6 & - Coding the Tic-Tac-Toe game & $0: 38: 52$ & Assignment \\
\hline
\end{tabular}

Table 2. Lesson videos

\subsection{Implementation of VFC}

As mentioned above, our research is based on the Active Learning (AL) approach, which offers a way of conceptualizing the learning process in four stages: Dialogue with Self, Dialogue with Others, Observing, and Doing. Figure 3 depicts the Active Learning approach (Johnson, Johnson \& Smith, 1998).

The researchers merged the Flipped Classroom (FC) and the Virtual Classroom (VC) with the AL approach to produce the VFC learning model. Various AL strategies are adopted in our research such as the find error strategy, collaborative learning groups strategy, and think-write-pair-share strategy (Petrina, 2006). Our new model introduces the dialogue part (with oneself and with others) as the first step towards applying the FC and the experience part as the second step. The second step is introduced within a virtual environment, or more precisely, within VC. Figure 4 shows the different stages of the VFC model, Sameh and Shubair Model. 


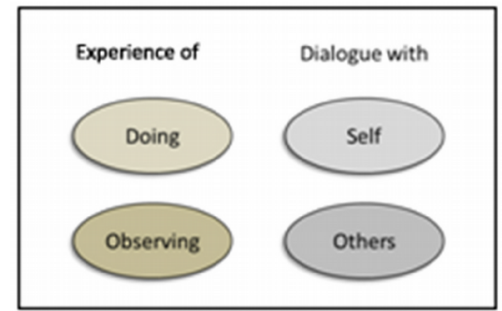

Figure 3. Active Learning approach (Fink, L.D., 2003)

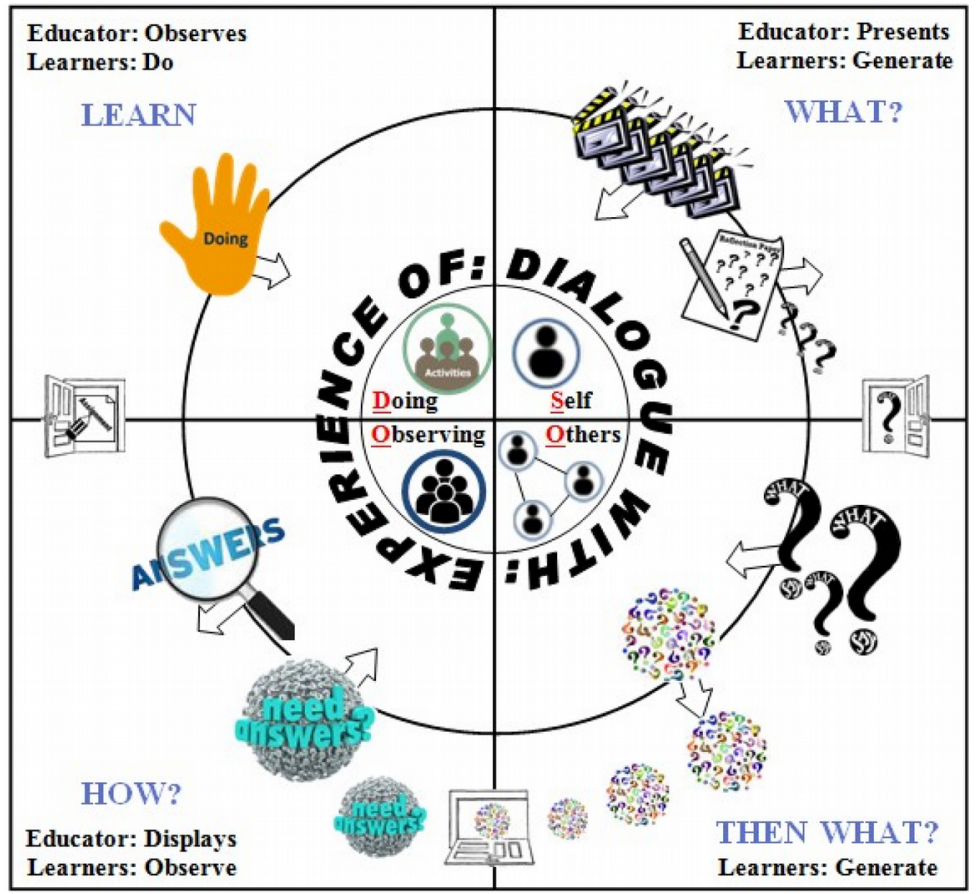

Figure 4. Stages of the VFC model

- Dialogue with Self: This is the first stage of VFC implementation. The main goal of this stage is to achieve self-learning and to develop learners into independent thinkers. The inputs of this stage were the videos prepared and sent by the educator. The learners watched the videos to go and interact deeply into the subject. After watching the videos, the learners had dialogues with themselves before they produced the output of this stage, which was a reflection paper as well as answering questions that begin with "What". Some questions were prepared by the educator, such as "What is the knowledge learned and skills acquired?" and "What is the role of this knowledge in the student's life?" Some other questions were prepared by the learners themselves, such as "What are the student's notes about the subject that has been learned?", "What are the difficulties faced during the learning?", and "What did the student learn?"

- Dialogue with Others: In this stage, the learner collaborated with colleagues about the output of the previous stage and its content. It happened when the learners were engaged in dialogue sessions with classmates to build mutual understanding of the video content and to review the questions prepared by the whole group during the previous stage, as well as the answers. This dialogue can be considered as "partial dialogue" as it might be limited to partial groups of the learners. The learners also engaged in dialogue situations outside of class under the monitoring of the educator using some creative technologies such as emails, mobile apps, and live chatting. The inputs of this stage were the questions and the answers that have been introduced by the learners and recorded in the reflection paper during the dialogue sessions. The conclusions of these dialogue sessions, i.e. the questions with no accurate answers, were considered as the outputs of the stage. Any unanswered questions should be presented to the educator for improved learning. 
- Observing: The events of the observing stage took place virtually in the virtual classroom. This stage aimed at providing learners with experiences through observing the activities performed by the educator or the learners during the virtual classroom. Initially, the educator presented an introduction to the topic, which had been sent previously to the learners. He also presented an introductory video or a final product created based on his prior expectation of the difficult points in the content elements. After that, the learners discussed their unanswered questions, which were considered as inputs for this stage. The learners then posted their notes about the videos and shared their thoughts with the educator and classmates virtually using the chat window or through the microphone. Finally, the educator started answering in a practical way the learners' questions. The answers given by the educator were the outputs of the observing stage.

- Doing: The doing stage was the final stage in the VFC model. The events of this stage took place in the virtual classroom. This stage aimed at giving learner experiences-by-doing through direct, purposeful experiences, which are what the students can learn by doing them. This way of teaching was done through assignments to solve real-world problems by writing computer programs, and these assignments were the inputs for this stage. The educator introduced the activities during the virtual classroom to make the learners apply what they have learned in the flipped classroom (the videos) and what they have observed in the virtual classroom. The activities done by the learners to solve the assignments were considered as the output of the stage. Both the observing and doing stage have been implemented using the WIZIQ platform. Figure 5 shows a snapshot of the WIZIQ platform where the students are online discussing and solving an assignment presented by the educator.

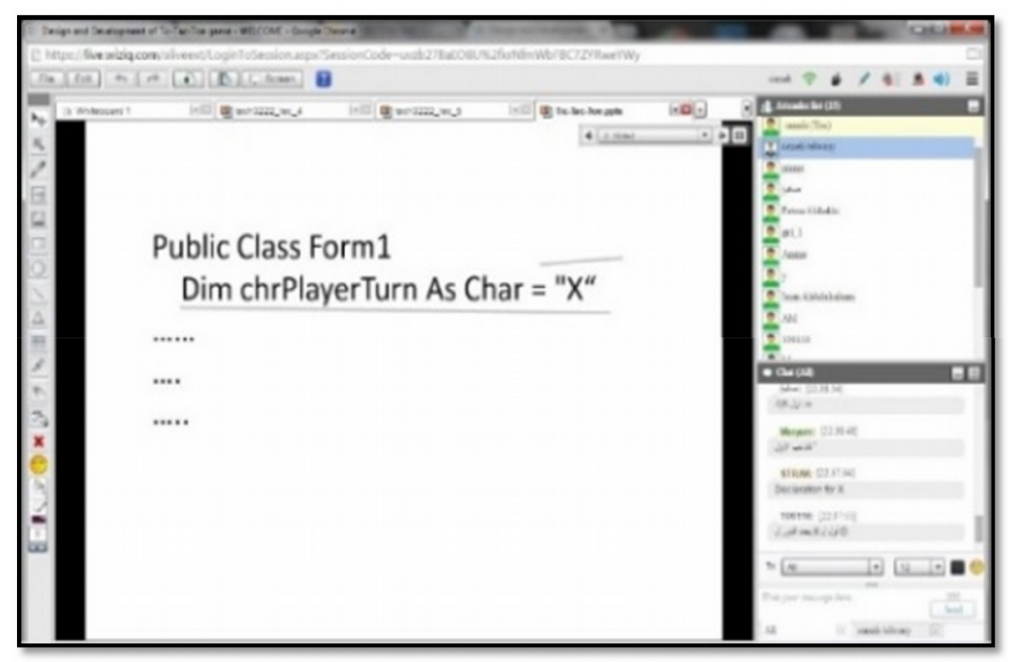

Figure 5. WIZIQ platform

In the WIZIQ environment, the educator presented an exercise to arrange the names of the students in descending order according to their grades. The exercise was a VB.NET program with a number of missing VB.NET instructions, and the student had to fill in the blanks with the appropriate instructions. The educator directed learners signed in in the class to complete the missing instructions. He gave the learners two minutes to think and answer. The educator then allowed the learners to respond according to the priority of participation by giving them the Handler to use the Whiteboard. The learner that had the Handler interacted with the class either through the Whiteboard or through audio. The answers were ordered according to the determination of the educator. The learner was not allowed to answer in a random manner and had to follow the order determined by the teacher. If the learner responded correctly, the educator allowed him to continue and answer the next instruction. Otherwise, the educator turned the Handler off in order to discuss the incorrect answers with the students. 


\section{Data Analysis and Results}

The tables and graphs show the results of applying the PAT and SSM instruments to test the students' level of learning and motivation. t-test analysis was conducted to determine if the pretest and posttest results are significantly different from each other. With respect to the level of motivation, one-way multivariate analysis of variance (MANOVA) was conducted with group as a between subject variable and attention, relevance, confidence, and satisfaction as dependent variables. All analyses were conducted using SPSS software. The statistical significance level was set at $\mathrm{p}<0.05$.

Learning Achievement, Knowledge and Problem Solving Pretest and Posttest

The t-test analysis was conducted to determine if the pretest and posttest results are significantly different from each other. This answers the second research question: Is the VFC effective in providing students the knowledge they need?

Table 3 shows the t-test results for PAT1 that measured the students' computer programming knowledge.

t-tests were also applied to answer the third research question: Is the VFC effective in solving problems in computer programming? Table 4 shows the t-test results for PAT2 that measured the students' ability to problem-solve in relation to computer programming.

Since the $(p)$ value was set at 0.05 , if the p-value was less than 0.05 , it could be concluded that there is a statistically significant difference between the means of the pretest and posttest scores in both versions. The values of 0.00191 in Table 3 and 0.00105 in Table 4 for $\mathrm{p}$ are both $<0.05$, and clearly show that the difference is significant. The final decision from the t-test results is to decide whether the VFC has an effect on the learning achievement. Figure 6 graphically depicts the differences between the pretest and posttest scores that are achieved by the learners in PAT1 and PAT2. Table 5 shows the students' achievement levels in PAT1 and PAT2 for the pretest and posttest. The scores of students in PAT1 and PAT2 are categorized into three levels: high $(>=8)$, average (6-7.9) and low $(<6)$. This scale has been adopted in SQU and it is followed in showing the results in Table 5.

\begin{tabular}{|c|r|r|r|c|}
\hline Type of Test & \multicolumn{1}{|c|}{$\mathbf{N}$} & \multicolumn{1}{c|}{ Mean } & \multicolumn{1}{c|}{ SD } & \multicolumn{1}{c|}{ P } \\
\cline { 1 - 4 } Pretest & \multirow{2}{*}{18} & 4.708 & 0.664 & \multirow{2}{*}{0.00191} \\
\cline { 1 - 1 } Posttest & & 7.639 & 2.347 & \\
\hline
\end{tabular}

Table 3. T-test results for PAT1

\begin{tabular}{|c|r|r|r|r|}
\hline Type of Test & \multicolumn{1}{|c|}{ N } & \multicolumn{1}{|c|}{ Mean } & \multicolumn{1}{c|}{ SD } & \multicolumn{1}{c|}{ P } \\
\cline { 1 - 4 } Pretest & \multirow{2}{*}{18} & 4.556 & 1.151 & \multirow{2}{*}{0.00105} \\
\cline { 1 - 1 } Posttest & & 8.639 & 0.612 & \\
\hline
\end{tabular}

Table 4. T-test results for PAT2
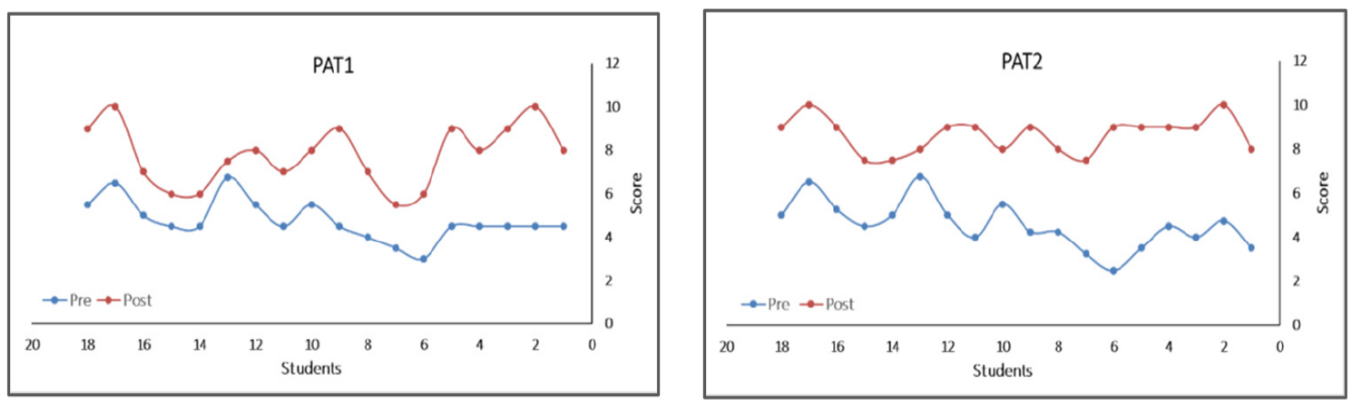

Figure 6. Differences between Pretest and Posttest scores for PAT1 and PAT2 


\subsection{Learning Motivation Pretest and Posttest}

The fourth question was also addressed: Is the VFC effective in increasing the motivation of the students to learn computer programming?

Learning motivation was analysed using the Survey of Student Motivation (SSM) which is divided into four dependent variables: attention, relevance, confidence, and satisfaction. We collected the survey data for perceived motivation both before and after applying the VFC model and then analysed the data with the repeated measure MANOVA. Descriptive statistics including means and standard deviation along with $P$ values are provided for the following dependent variables: attention, relevance, confidence, and satisfaction (Table 6). The analysis results reveal that there are marginable differences in the values of means of all dependent variables before and after applying the VFC model, and these differences are significant since that $P$ values for all dependent variable are $<0.05$. The results indicate that there are differences in learners' attention, relevance, confidence, and satisfaction before and after applying the VFC model. The differences indicate the positive impact of the VFC model since the means of dependent variables after applying the VFC are higher than the corresponding values before applying the VFC model. Figure 7 depicts the students' scores in SSM pretest and posttest for the four variables of attention, relevance, confidence, and satisfaction.

\begin{tabular}{|r|c|c|r|r|r|}
\hline \multirow{2}{*}{ PAT } & \multicolumn{2}{|c|}{ Test } & \multicolumn{1}{c|}{ High } & Average & \multicolumn{1}{c|}{ Low } \\
\hline \multirow{3}{*}{ PAT1 } & \multirow{3}{*}{ Pre } & Frequency & 0 & 2 & 16 \\
\cline { 3 - 6 } & & Percentage & $0 \%$ & $11 \%$ & $89 \%$ \\
\cline { 3 - 6 } & \multirow{2}{*}{ Post } & Frequency & 10 & 4 & 4 \\
\cline { 3 - 6 } & \multirow{3}{*}{ Pre } & Percentage & $56 \%$ & $22 \%$ & $22 \%$ \\
\cline { 3 - 6 } & & Frequency & 0 & 4 & 16 \\
\cline { 3 - 6 } & \multirow{3}{*}{ PAT2 } & Percentage & $0 \%$ & $25 \%$ & $75 \%$ \\
\cline { 3 - 6 } & \multirow{2}{*}{ Post } & Frequency & 15 & 3 & 0 \\
\cline { 3 - 6 } & & Percentage & $83 \%$ & $17 \%$ & $0 \%$ \\
\hline
\end{tabular}

Table 5. Frequency and percentage distribution of learners

\begin{tabular}{|c|c|c|c|c|c|}
\hline Motivation & Test Type & $\mathbf{N}$ & Mean & SD & $\mathbf{P}$ \\
\hline \multirow{2}{*}{ Attention } & Pretest & \multirow{8}{*}{18} & 2.05 & 0.808 & \multirow{2}{*}{0.0062} \\
\hline & Posttest & & 3.28 & 1.007 & \\
\hline \multirow{2}{*}{ Relevance } & Pretest & & 2.04 & 0.771 & \multirow{2}{*}{0.0056} \\
\hline & Posttest & & 3.21 & 1.075 & \\
\hline \multirow{2}{*}{ Confidence } & Pretest & & 2.15 & 0.757 & \multirow{2}{*}{0.0002} \\
\hline & Posttest & & 3.33 & 1.308 & \\
\hline \multirow{2}{*}{ Satisfaction } & Pretest & & 1.88 & 0.811 & \multirow{2}{*}{0.0035} \\
\hline & Posttest & & 3.26 & 1.258 & \\
\hline
\end{tabular}

Table 6. MANOVA test of learners' motivation 

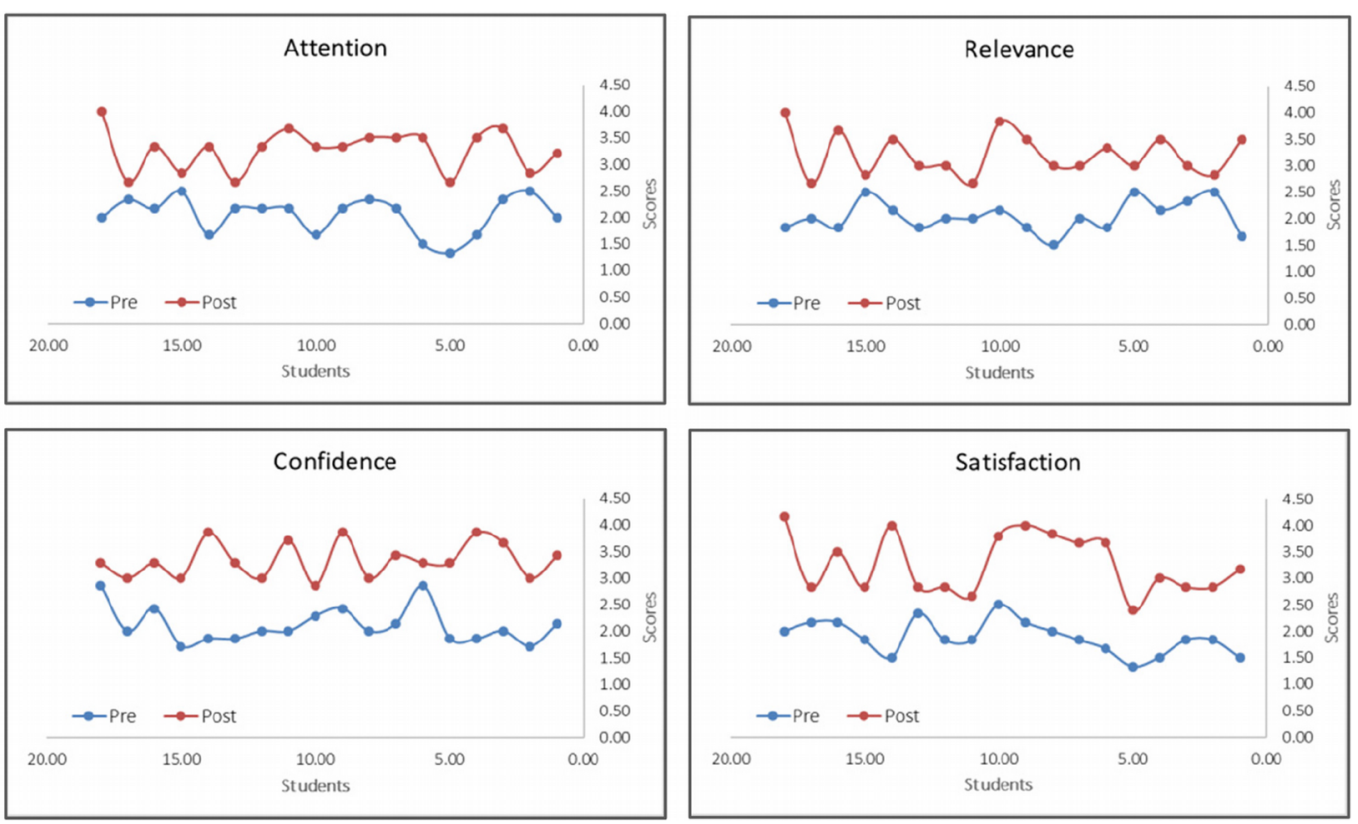

Figure 7. Students' score in SSM Pretest and Posttest scores

\section{Discussion and Conclusion}

The present study investigates the VFC as a new model to deliver the required prerequisite knowledge to students. The researchers faced challenges when comparing the results of this study with other studies. This is because this research is considered as the first attempt to integrate the concepts of VC and FC into a new teaching model, the VFC, according the researchers' knowledge. To overcome this issue, the researchers compared the study results with the research results associated with each concept separately. The experiments were conducted to measure the students' levels of learning the prerequisite knowledge of computer programming and their motivation to study the computer programming content. Afterwards, the researchers investigated the levels of learning and the levels of motivation before and after applying the VFC.

The statistical results indicated that the students' learning achievement increased significantly after applying the VFC as noted from Table 3 which shows the PAT1 results. The significant differences between the mean scores of the pretest and posttest show that the posttest is larger. The reasons for these differences are explained below:

- The application of FC has supported learning and the understanding of video lessons. This is mainly because of its potential to simplify the course content through multimedia videos comprised of examples of code along with instructional SWF files. This kind of video supports learning various scientific subjects. This result supports the findings of previous studies (Thai, De Wever \& Valcke, 2017; Al Zahrani, 2015).

- The videos presented provided the opportunity for students to repeat the lessons at any time and to focus on anything that was not clear. They were also able to record their inquiries and discuss them either with classmates via social media (done in the "dialogue with others" stage within the $\mathrm{AL}$ ) or with the teacher via the VC (done in the "observing" stage within the AL) (Seidel, Blomberg \& Renkl, 2013; van der Meij, 2017).

- The possibilities offered by the use of VC for students to record and repeat any part of the virtual lectures (O’Callaghan, Neumann, Jones \& Creed, 2017). This specifically helps the students to repeat teacher's answers to their inquiries in practice, which might be unanswered during the first and second stages of the VFC model. 
- The positive impact that AL can have upon students' learning outcomes. The AL environment provides the students with the opportunity to think critically, search for inquiries, and acquire technological communication skills. In addition, AL can increase students' enthusiasm for communicating with classmates and building healthy social relationships (Thaman, Dhillon, Saggar, Gupta \& Kaur, 2013).

The PAT2 was designed to measure students' ability to solve programming problems. The results revealed the existence of statistically significant differences between the students' mean pretest and posttest scores. This can be noted from the $\mathrm{P}$ value, which equals 0.00105 . The following points summarize the reasons behind the PAT2 result:

- The lessons were introduced by following the FC concept. The students had sufficient time to replay the videos of lessons. They were able to think about the questions and programming problems posed by the teacher; hence they searched, tested, and shared solutions to the problems before meeting the teacher during the VC.

- The AL environment of the VFC model allowed the students to share ideas to solve the problems posed by the teacher by applying AL strategies such as find error, collaborative learning groups, and think-write-pair-share (Petrina, 2006).

- The experiences acquired by the students by discussing and examining different ideas of their classmates during the VC provided them with the skills needed to solve programming problems.

- The use of VC contributed to the treatment of some students' psychological problems such as anxiety of failure and shyness (Johnston, Killion \& Oomen, 2005).

- Multiple learning resources not available in the traditional classroom are provided through the application of the VFC model (Park \& Choi, 2014).

Table 5 shows numerically the increases in the level of student achievement in the posttest by categorizing the students into three levels: low, average, and high. With regards to PAT1 results, 10 students $(56 \%$ of the students) are categorized high level (score $>=8), 4$ students (22\% of the students) are categorized average level (score from $6-7.9)$, and 4 students $(22 \%$ of the students) are categorized low level $($ score $<6)$. The reason for the failure of 4 students to achieve a score greater than 6 in the posttest is that some were not accustomed to the virtual learning environment. Rather, they more accustomed to traditional teaching methods in which the teacher's role involves only standing in front of them, lecturing, and discussing inquiries face-to-face with them. On the other hand, the results are more encouraging in PAT2: $83 \%$ were high level, 17\% average level, and $0 \%$ low level. Both of the PAT1 and PAT2 results indicate that the application of the VFC model helps the students to improve their performance in computer programming. The researchers attribute the reason to the fact that the teacher is able to give the students more attention which allows more discussion and understanding during application of the VFC model.

Concerning the levels of motivation, the results shown in Table 6 reflect the statistically significant differences between the mean scores of SSM pretest and posttest, with the latter being greater. The researchers attribute the differences to the use of the VFC model, which is based on the FC and VC concepts. The FC concept reduced the level of stress and raised the level of positive feelings of the students in relation to studying computer programming. This is obvious in their attempts to answer the formative evaluation questions posed in the video lessons and in their inquiries raised after viewing the video lessons. They were motivated to answer the inquiries through the collaborative AL activities during the first two stages of VFC ("dialogue with self" and "dialogue with others"). The results support the findings of previous studies (Marlowe, 2012). The social interaction during the VC had a positive impact on students' motivation and contributed to the success of learning opportunities. The enthusiasm, interaction, and collaboration were noticed in all virtual meetings in VC, which added an element of fun initiated from the interaction of students with each other and their interaction with the instructor in a 
initiated from the interaction of students with each other and their interaction with the instructor in a positive social environment with an obvious AL during the third and fourth stages of the VFC ("observing" and "doing"). The researchers confirm that the VC contributed to developing the relevance feeling toward the classroom society and lesson content because they were keen to attend the VC before the beginning of the lesson. This result supports the findings of previous studies (Parker \& Martin, 2010), which concluded that learning in the VC is achieved by participating in communities and exchanging experiences with other learners through relationships based on communities of practice.

Figure 7 illustrates the responses of our sample, 18 students for SSM items before and after applying VFC. The variables (attention, relevance, confidence, and satisfaction) improved after applying the VFC model. The researchers attribute this improvement to the effectiveness of the VFC model stages that result in raising the interest of students in learning computer programming and consequently raising the attention and the relevance level. A reduction in the level of stress resulted from passing the PAT1 and PAT2 tests and has a positive impact on the level of confidence. This has been reflected in the results of satisfaction toward learning the computer programming and let them satisfied their understanding. These results are in line with Dewey's practice theory (Petrina, 2006) which proposes that active work leads to knowledge because students gain positive experiences which initiates the tendency to like the active work more and more.

The students of the Department of Instructional and Learning Technologies at the College of Education lack the prerequisite knowledge that qualifies them to study computer programming. Thus, it is necessary to develop teaching models to help them better understand the concepts of computer programming. The present research has contributed to computer programming education by providing practical evidence of the potential of the VFC model. To conclude, with the advancement of technology and the adoption of the VFC model, both teaching and learning computer programming can be made more effective and enjoyable. Based on this, the researchers recommend the use of the VFC model in similar cases where it is difficult to change the system of academic hours related to the courses and academic programs.

\section{Declaration of Conflicting Interests}

The authors declared no potential conflicts of interest with respect to the research, authorship, and/or publication of this article.

\section{Funding}

The authors received no financial support for the research, authorship, and/or publication of this article.

\section{References}

$\mathrm{Al}$ Zahrani, A.M. (2015). From passive to active: The impact of the flipped classroom through social learning platforms on higher education students' creative thinking. British Journal of Educational Technology, 46(6), 1133-1148. https://doi.org/10.1111/bjet.12353

Allmendinger, K., Kempf, F., \& Hamann, K. (2009). Collaborative learning in virtual classroom scenarios. Learning in the Synergy of Multiple Disciplines, 344-349. https://doi.org/10.1007/978-3-642-04636-0_33

Bergmann, J., \& Sams, A. (2012). Flip your classroom: Reach every student in every class every day: International Society for Technology in Education.

Bergmann, J., \& Sams, A. (2014). Flipped learning: Gateway to student engagement: International Society for Technology in Education.

Choi, I., Kopcha, T., Mativo, J., Hill, R., Hodge, E., Shin, S. et al. (2016). Learning Computer Programming in Context: Developing STEM-integrated Robotics Lesson Module for 5th Grade. Paper presented at the Society for Information Technology \& Teacher Education International Conference. 
Fink, L.D. (2003). A Self-Directed Guide to Designing Courses for Significant Learning. Available at: http://www.bu.edu/sph/files/2011/06/selfdirected1.pdf (Accessed: July 2017)

Hamdan, N., McKnight, P., McKnight, K., \& Arfstrom, K.M. (2013). Flipped Learning Model: A White Paper Based on the Literature Review Titled "A Review of Flipped Learning". White Paper Flipped Learning, 1-16.

Ismail, S., \& Shubair, A. (2015). Design and Implementation of an Intelligent System to Predict the Student Graduation AGPA. Australian Educational Computing, 30(2).

Johnson, D.W., Johnson, R.T., \& Smith, K.A. (1998). Active learning: Cooperation in the college classroom. ERIC.

Johnston, J., Killion, J., \& Oomen, J. (2005). Student satisfaction in the virtual classroom. Internet Journal of Allied Health Sciences and Practice, 3(2), 6.

Kahn, K., \& Spiegel, H.L. (1999). The role of computer programming in education. Educational Technology ¿. Society, 2(4), 6-9.

Keller, J.M. (1999). The ARCS model. Designing motivating instruction. Unpublished manuscript.

Lietzau, J.A., \& Mann, B.J. (2009). Breaking out of the asynchronous box: Using web conferencing in distance learning. Journal of Library \& Information Services in Distance Learning, 3(3-4), 108-119. https://doi.org/10.1080/15332900903375291

Long, T., Logan, J., \& Waugh, M. (2016). Students' perceptions of the value of using videos as a pre-class learning experience in the flipped classroom. TechTrends, 60(3), 245-252. https://doi.org/10.1007/s11528016-0045-4

Lye, S.Y., \& Koh, J.H.L. (2014). Review on teaching and learning of computational thinking through programming: What is next for K-12? Computers in Human Behavior, 41, 51-61.

https://doi.org/10.1016/j.chb.2014.09.012

Marlowe, C.A. (2012). The effect of the flipped classroom on student achievement and stress. Master in Education Thesis. Montana State University (MSU).

Martin, F., \& Parker, M.A. (2014). Use of synchronous virtual classrooms: Why, who, and how? Journal of Online Learning and Teaching, 10(2), 192.

Martin, F., Parker, M.A., \& Deale, D.F. (2012). Examining interactivity in synchronous virtual classrooms. The International Review of Research in Open and Distributed Learning, 13(3), 228-261. https://doi.org/10.19173/irrodl.v13i3.1174

O’Callaghan, F.V., Neumann, D.L., Jones, L., \& Creed, P.A. (2017). The use of lecture recordings in higher education: A review of institutional, student, and lecturer issues. Education and Information Technologies, 22(1), 399-415. https:// doi.org/10.1007/s10639-015-9451-z

Park, E.L., \& Choi, B.K. (2014). Transformation of classroom spaces: traditional versus active learning classroom in colleges. Higher Education, 68(5), 749-771. https://doi.org/10.1007/s10734-014-9742-0

Park, N. (2016). Development of computer education program using LOGO Programming and fractals learning for enhancing creativity: Focus on creative problem-solving. International Journal of u-and e-Service, Science and Technology, 9(2), 121-126. https://doi.org/10.14257/ijunesst.2016.9.2.13

Parker, M.A., \& Martin, F. (2010). Using virtual classrooms: Student perceptions of features and characteristics in an online and blended course. Journal of Online Learning and Teaching, 6(1), 135. 
Patrick, L.E., Howell, L.A., \& Wischusen, W. (2016). Perceptions of Active Learning between Faculty and Undergraduates: Differing Views among Departments. Journal of STEM Education: Innovations and Research, 17(3), 55.

Petrina, S. (2006). Advanced teaching methods for the technology classroom. IGI Global.

Seidel, T., Blomberg, G., \& Renkl, A. (2013). Instructional strategies for using video in teacher education. Teaching and Teacher Education, 34, 56-65. https://doi.org/10.1016/j.tate.2013.03.004

Sesen, B.A., \& Tarhan, L. (2010). Promoting active learning in high school chemistry: Learning achievement and attitude. Procedia-Social and Behavioral Sciences, 2(2), 2625-2630. https://doi.org/10.1016/j.sbspro.2010.03.384

Slomanson, W.R. (2014). Blended learning: A flipped classroom experiment. Journal of Legal Education, 64(1), 93-102.

Sun, J.C.-Y., \& Wu, Y.-T. (2016). Analysis of learning achievement and teacher-student interactions in flipped and conventional classrooms. The International Review of Research in Open and Distributed Learning, 17(1). https://doi.org/10.19173/irrodl.v17i1.2116

Sun, J.C.-Y., Wu, Y.-T., \& Lee, W.-I. (2017). The effect of the flipped classroom approach to OpenCourseWare instruction on students' self-regulation. British Journal of Educational Technology, 48(3), 713-729. https://doi.org/10.1111/bjet.12444

Szarek, J.L., Boardman, J.M., White, M., \& Holt, J.T. (2016). Integrated and flipped: 5 years' experience of integrating active learning in an integrated course. Medical Science Educator, 26(1), 159-167.

https://doi.org/10.1007/s40670-015-0214-7

Thai, N.T.T., De Wever, B., \& Valcke, M. (2017). The impact of a flipped classroom design on learning performance in higher education: Looking for the best "blend" of lectures and guiding questions with feedback. Computers \& Education, 107, 113-126. https://doi.org/10.1016/j.compedu.2017.01.003

Thaman, R., Dhillon, S., Saggar, S., Gupta, M., \& Kaur, H. (2013). Promoting active learning in respiratory physiology-positive student perception and improved outcomes. National Journal of Physiology, Pharmacy and Pharmacology, 3(1), 27-34. https://doi.org/10.5455/njppp.2013.3.27000

Thomson, D.L. (2010). Beyond the classroom walls: Teachers' and students' perspectives on how online learning can meet the needs of gifted students. Journal of Advanced Academics, 21(4), 662-712. https://doi.org/10.1177/1932202X1002100405

van der Meij, H. (2017). Reviews in instructional video. Computers \& Education, 114, 164-174. https://doi.org/10.1016/j.compedu.2017.07.002

Published by OmniaScience (www.omniascience.com) Journal of Technology and Science Education, 2019 (www.jotse.org)

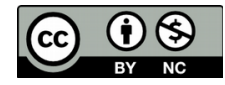

Article's contents are provided on an Attribution-Non Commercial 4.0 Creative commons International License. Readers are allowed to copy, distribute and communicate article's contents, provided the author's and JOTSE journal's names are included. It must not be used for commercial purposes. To see the complete licence contents, please visit https://creativecommons.org/licenses/by-nc/4.0/. 